\title{
Interpreting intraplate tectonics for seismic hazard: A UK historical perspective
}

\author{
RMW Musson \\ British Geological Survey \\ West Mains Road \\ Edinburgh EH9 3LA \\ $U K$ \\ +441316500205 (tel) \\ +441316671877 (fax) \\ rmwm@bgs.ac.uk
}




\begin{abstract}
It is notoriously difficult to construct seismic source models for probabilistic seismic hazard assessment in intraplate areas on the basis of geological information, and many practitioners have given up the task in favour of purely seismicity-based models. This risks losing potentially valuable information in regions where the earthquake catalogue is short compared to the seismic cycle. It is interesting to survey how attitudes to this issue have evolved over the past 30 years.

This paper takes the UK as an example, and traces the evolution of seismic source models through generations of hazard studies. It is found that in the UK, while the earliest studies did not consider regional tectonics in any way, there has been a gradual evolution towards more tectonically-based models. Experience in other countries, of course, may differ.
\end{abstract}

\title{
Keywords
}

Seismic hazard, seismic source model, tectonics, seismotectonics, intraplate, UK, history of seismology

\section{Introduction}

Probabilistic seismic hazard assessment (PSHA) is a subject that has seen rapid methodological developments since it was first introduced just over 40 years ago. The pace at which developments continue is still rapid, and practices that might have seemed acceptable just ten years ago would now be frowned upon. This has been particularly true in the ground motion modelling community, and one can point to the way in which this aspect of PSHA has been transformed in recent years, firstly by the Next Generation Attenuation (NGA) project (Power et al. 2008), and also recent papers on how ground motion models can be evaluated and compared (Scherbaum et al. 2009, Bommer et al. 2010).

Issues of seismic source characterisation have not attracted quite as much attention. In this part of a PSHA project, the analyst attempts to define a model representing the separate sources of earthquakes that are relevant to the analysis in hand. In this context, a source can generally be considered to be one of three things. Firstly, a seismogenic fault that has produced earthquakes in the past, and can be expected to continue to do so. Secondly, an assemblage of such faults sufficiently close and similar that it is advantageous to treat them together as a group. Thirdly, an area within which seismogenic conditions appear homogeneous, and one can reasonably state that there is an equal chance of an earthquake anywhere within the defined area. The second and third types of source are essentially the same; both are treated as areas (or volumes, to be absolutely precise). The difference in definition is that one is made up of a known fault population, and in the other, while it may be considered that patterns of faulting are consistent throughout the area, individual faults may not be easy to ennumerate.

In areas of active tectonics, it is relatively straightforward to describe the main geological structures and seismogenic features, though not always without controversy. In intraplate areas, the task can be harder, since it is often the case that one can see clear spatial 
variations in seismicity that do not obviously correlate with any geological feature. The possible interpretations can be many and varied. A classic case is the study of Central and Eastern USA in Bernreuter et al (1989) in which different experts produced widely differing models of the same area. The lack of agreement in interpretation was almost certainly a factor in fuelling interest in methods that abandoned area zones altogether in favour of a smoothed seismicity approach (Frankel et al 1996, Woo 1996).

However, smoothed seismicity approaches have their own problems. It is often stated that they are "objective" where area sources are "subjective". But (and despite various "autotuning" systems) the choice of one smoothing system over another is essentially a subjective decision. In any case, subjective expert decisions are sometimes to be preferred to rule-based objective ones, which is why medical services generally use doctors and not computer programs to diagnose patients. This is particularly pertinent in the case of the matter in hand; the earthquake catalogue is but one type of information available that is relevant to seismogenesis, and is often relatively short compared to the seismic cycle. To depend completely on manipulation of the earthquake catalogue is therefore risky. A criticism made of the extreme value approach to seismic hazard, made many years ago by Knopoff and Kagan (1977), was the simple question, is it credible that one can get better results by throwing away most of one's data? The same is apposite here.

Therefore, rather than shirking the task of interpreting structural geology in intraplate areas, it is perhaps better to make a more sustained effort at solving the problem. One contribution, outlined in Musson (2004) and Musson and Winter (2011), is to test seismic source models to see if they can reproduce the historical seismicity. Such tests would have eliminated many of the models proposed in Bernreuter et al (1989).

The British Isles is an area where these questions are highly pertinent. It is far from any plate margin. The nearest plate boundaries are the mid-Atlantic to the north-west, and the northern edge of the Adria Plate to the south-east. The seismicity is generally low (the earthquake with recurrence interval of one year is $3.5 \mathrm{Mw}$ ), but sufficient for earthquake hazard to be something that needs to be taken into consideration for nuclear safety. The seismicity is also very heterogeneous (see Figure 1). Ireland in particular is virtually aseismic, and the apparent absence of earthquakes is not due to any lack of historical records, but is genuine. Various hypotheses have been put forward over the years to try and explain this irregular distribution, and these are surveyed in Musson (2007).

The purpose of the present paper is not to present any new interpretation, but to trace how the issue has been treated by various PSHA studies over the decades. It should be considered as belonging to the literature of the history of seismology. Obviously, it is necessarily restricted to studies that are not restricted by confidentiality.

\section{Beginnings of seismic hazard studies in the UK}

The first recognisable hazard study of the UK, in the sense of plotting some form of ground motion values with an associated probability, seems to be that of Lilwall (1976). The output from this study was a hazard map of Great Britain plotting macroseismic intensities with a 200 year return period. The intensity scale used was the eccentric Davison Scale (Davison 1900), based loosely on the Rossi-Forel Scale. This is possibly the last time this scale ever saw use. The map is shown in Figure 2. The method used was an extreme value approach following Milne and Davenport (1969). It is therefore based 
entirely on processing of the earthquake catalogue and contains no geological input whatever.

The first use of what is recognisably PSHA in the sense of Cornell (1968) was made by Irving (1979) for what was then the Central Electricity Generating Board. It was only in the late 1970s that it was properly appreciated that seismic risk was relevant to nuclear power in the UK. Irving's (1979) study was extremely simple in approach, in that he assumed that seismicity could be treated as completely uniform, and a single average value of hazard obtained for the whole country. Because it was the first study, and perhaps particularly because it sought to compute "average" hazard, Irving's (1979) result was long afterwards used as a mental anchor for subsequent studies in judging whether they were "high" or "low". This despite the fact that the earthquake catalogue and ground motion model used by Irving were to be greatly improved on in subsequent years.

In an update, Irving (1982) divided the UK into ten source zones. Remarkably, this was done on a purely geographical basis, with no reference to anything beyond what common parlance would consider to be different regions. Irving's rationale seems to have been that where one draws zone boundaries is immaterial, because one simply proceeds to assess the seismicity rates that pertain to any zone. "Without recourse to tectonic regionalization it can be concluded ... that the rough regional boundaries ... can be used to rank regions in order of their seismic density per unit area ..." (Irving 1982). It does not seem to have occurred to Irving that, if the regions are not homogeneous with respect to earthquake generation, then the PSHA method is invalid.

\section{Seismic hazard and nuclear power}

Starting in 1980, a very large effort was put into improving knowledge of British seismicity, much of which was funded by the nuclear industry. This was mostly undertaken by two private consultancies, by Imperial College London, and by the British Geological Survey (BGS). Key reports are Principia Mechanica (1982), Soil Mechanics (1982), Ambraseys and Melville (1983), and Burton et al (1984).

These studies were followed by a number of seismic hazard studies for individual nuclear power plants, many of which were carried out by the Seismic Hazard Working Party (SHWP), an informal alliance of individual consultants. A typical example is SHWP (1987), for the Hinkley Point site in Somerset. A large amount of extensive geological investigation went into the SHWP studies, which was particularly directed to investigation of capable faulting, and the identification of individual faults considered to require modelling as discrete structures in the PSHA. The SHWP reports also contain extensive discussion of regional tectonic setting, but it is not always clear to what extent this is really translated into the seismic source modelling. The models used were characteristically highly geometrical.

Figure 3 is an example, redrawn from SHWP (1987); it contains seven area zones and one fault that is explicitly modelled due to its closeness to the site. It will be noticed that all zones are simple quadrilaterals, always with sides running north-south (with respect to the UK National Grid, which explains the tilt in Figure 3, in which the model has been redrawn in latitude and longitude). These zone boundaries mostly cut across tectonic boundaries; the resulting zones are also often inhomogeneous with respect to seismicity. On the other hand, it can easily be countered that there is no need for making refinements 
to a zone model than have minimal impact on hazard at site. Thus a very crude approach to zonation at distances greater than about $100 \mathrm{~km}$ (or possibly less) is defensible. Such very simple zones can also sometimes result from limitations of early PSHA software.

\section{National studies}

At the beginning of the 1990s, the nearest there was to a map of seismic hazard in the UK was still that of Lilwall (1976), and that was hardly usable, owing to its eccentric intensity scale (it was also well out of date, thanks to all the work that had been undertaken in the 1980s). The first study to address this was commissioned by the Department of the Environment to produce a comprehensive overview of both seismic hazard and risk in the UK. It was undertaken by Arup (1993). This study chose not to calculate actual hazard maps; possibly due to restrictions of computer software and hardware at that date. Instead, Arup (1993) opted to calculate seismic hazard values for eleven cities spaced more or less evenly over the country, including Belfast, in Northern Ireland.

The source model used was interesting, consisting of three alternative models, each covering the whole of the UK, which were combined in a logic tree structure. This was certainly the first time contrasting models had been used in this way in a British PSHA. The first, as in Irving (1979), assumes that seismicity is homogeneous over the whole country. As subsequent analysis was to show (Musson 2000), this hypothesis is untenable, but in 1990 when the project began, it was a matter of debate. The second model is purely seismicity-based, defining three simple zones of higher seismicity against a background of lower activity. The third is the more interesting from the point of view of the present paper (Figure 4). The intention behind this third model was to define a zonation entirely based on neotectonic considerations.

This relied entirely on a study by Muir Wood (1989), who traced the evolution of the British Isles and surrounding area since the middle Eocene. Muir Wood identified several broad zones of significant deformation that had operated from the Eocene to the late Miocene, and proposed that areas within these deformation zones were more susceptible to present-day seismicity. Arup (1993) translated this into a zone model in which the UK is partitioned into areas that were subjected to deformation more than once, once, or not at all in the last 50 million years.

The rationale of the logic tree was therefore to balance what one might consider a longterm overview based purely on neotectonics with a more immediate model based on historical seismicity. This was somewhat undermined by the addition of the uniform seismicity model, which had the effect of diluting any contrasts, without being supported by any evidence. As the multiple-deformation zone grouped together some of the highest seismicity parts of the UK (e.g. North Wales) with some of the lowest (e.g. Northern Ireland) the distribution of the final results was rather unintuitive.

Very shortly afterwards, a set of hazard maps for the UK offshore area was commissioned by the Offshore Department of the Health and Safety Executive, as a collaboration between Arup and BGS. Although this work was completed in 1992, due to administrative delays it was not published until five years later (Musson et al 1997), and thus appears out of place in the chronological sequence. 
This was the first time that fully probabilistic seismic hazard maps had been produced in the UK; the problems of sufficient computing resources were solved by the use of facilities provided by Edinburgh University, who made time available on an experimental advanced machine. The hazard contours in the maps covered only the UK's territorial waters, and land areas were blanked out. However, the source model covered the entire area from Denmark to the mid-Atlantic ridge. For the North Sea, the association between seismicity and structure is more apparent than in the mainland UK; seismicity is linked to major graben structures such as the Viking Graben, and lacking from structural highs such as the Horda platform. The seismicity of the Central Graben is more debatable, particularly since it has been subsequently shown that at least some of the seismicity in the central North Sea has been induced (Ottemöller et al. 2005).

The onshore zonation in Musson et al (1997) is, however, primarily defined with respect to seismicity, with the stated objective of "[isolating] zones of uniform earthquake activity ... rather than to give primacy to modelling the geological features". Even so, it is clear from the descriptions of some of the zones that geological or tectonic factors (including Oligocene deformation) were used in refining zone boundaries.

Soon after the offshore study had been completed (i.e. around 1994) a further project, again as a result of a government commission, was started to produce the first onshore hazard maps for the UK. This work was a collaboration between BGS and what was then AEA Technology. Whereas the offshore study had used the well-known PSHA program SEISRISK III (Bender and Perkins 1987), this new study developed a program SUNMIC, an adaptation of SEISRISK III that allowed the use of logic trees. (Musson and Winter 1996, 1997).

The source model was somewhat experimental in nature. It consisted of two models yoked together in a logic tree. The first of these was based largely on that used by the offshore study. The second consisted of a large number of small "soft-boundary" zones placed around significant earthquakes or centres of earthquake activity. The effect of this was extremely similar to that of smoothed seismicity techniques, but achieved through controlled use of conventional area-zone methods (which are more flexible than they are often given credit for). The stated aim was not to use the logic tree as representative of either-or epistemic uncertainty, but to give a combined effect in the final hazard maps, whereby the broad zones in the first model gave the general contours of hazard, while extra local detail was provided by the influence of the small zones related to past significant events (Musson 1997).

Development of the first, "tectonic" branch of the model continued after Musson and Winter (1996) in the context of the GSHAP (Global Seismic Hazard Assessment Programme), though the basis was still the definition of zones within which the seismicity was homogeneous (not uniform, which carries a different meaning) and informed where possible by tectonic considerations (Grünthal et al 1996, 1999). This model has proved robust. It reappeared in the SESAME project (Jiménez et al 2001), and was used in a testing exercise in Musson (2004), Musson and Winter (2011) and shown to give good consistency with the historical record. This model is shown in Figure 5.

One unrelated mapping study around the same period was published by EQE (2002) as a result of a collaboration with NORSAR. This concentrated on the seismic hazard of the North Sea, and, as in Musson et al (1997), the hazard contour maps show land areas 
blanked out. This study also used two models, but in this case the models were rather similar. In each case the starting point was a NORSAR model for Norway and Norwegian waters, which was then extended westwards. The two NORSAR models were firstly, that used for national hazard studies, and secondly, a simplified version used for GSHAP. Accordingly, the extension of the first model over the UK area was relatively detailed, while the extension of the second was simplified. In some cases in the second model, zones are combined; the second model has a zone in which all of Wales, the Irish Sea and the English Midlands are bundled together, despite dissimilarities, while in the first model five separate zones are used for this area. Other zones are unchanged, and others are slightly modified for undocumented reasons.

The report states firstly, that "the basic principle underlying a zonal partition" is to establish homogeneity of seismological characteristics. However, it also states that "the principal seismotectonic characterization of Northwest Europe ... is the framework underlying the construction of the two EQE zonations ..." (EQE 2002), without further reference. From the individual zone descriptions, one can infer that again, a compromise has been sought between tectonics and seismicity. Some zones are named after tectonic features, such as "Iapetus Suture", "Midland Microcraton", and "London-Brabant" [Massif]. Others have geographical names and descriptions that indicate they are primarily defined by their seismicity - "this active zone includes South Yorkshire and Lancashire, Derbyshire and Nottinghamshire, which constitute a major seismic belt ..." (EQE 2002).

\section{Recent developments}

In the mid 2000s, a new national seismic hazard study was commissioned, expressly for the purpose of being used with the UK National Annex to the Eurocode 8 building code (Booth 2008). For this model, a new approach was taken, with the intention of starting with a tectonic model, and then informing the model with the seismicity distribution, rather than the other way round (Musson and Sargeant 2007).

A suggested approach to zonation has been published in Musson et al (2009) based on work done in the PEGASOS project (Abrahamson et al 2002) at the beginning of the decade. This envisages a three-stage process:

"The first stage involves the determination of the kinematic model. This is the basic element of the conceptual model of the seismic process at a sub-continental scale. The kinematic model describes, at the broadest scale, what is the relationship between large blocks in the Earth's crust in terms of relative movement ... This describes the basic mechanisms for earthquakes that are to be expected in different parts of the area under examination. The second stage refines the kinematic model into the seismotectonic framework. In this part of the process, the very broad divisions used in the kinematic model are looked at in more detail, with the aim of dividing them up into volumes of crust that are sufficiently structurally distinct that it is improbable that seismicity could be considered to be uniform across the boundaries of such divisions ... one is seeking to characterise areas that have a similar style of faulting, are experiencing a similar pattern of crustal stresses, and so on ... The third stage is the final construction of the seismic source definition. Here the final partition of the seismic source model is made from 
analysis of the seismotectonic framework together with the detailed pattern of observed seismicity and local geological structure." (Musson et al 2009)

The basis of the new model was an extensive study of the tectonics of the UK carried out by Chadwick et al. (1996). This included the preparation of a seismotectonic model for the UK (Figure 6), with divisions made on the basis of zones representing "the surface projections of subsurface volumes of characteristic upper crustal geological structure" (Chadwick et al 1996). The same report also includes a kinematic model that attempts to show how the major structural blocks respond to the overall crustal stresses applied as a result of Atlantic opening, and how this is likely to induce areas of stress concentration and stress shadow (see also Musson 2007).

Chadwick et al.'s (1996) zones are classified according to a system that starts with the geological terrane (e.g. Scottish Caledonides) and then numbers individual zones according to characteristic divisions within each terrane. Thus the zones that make up the area of the Scottish Caledonides have identifying codes SC1, SC2, etc. These formed the basis of the model developed by Musson and Sargeant (2007). One can start with the premise that, for an area to be homogeneous in seismicity, it should to some extent be consistent in general geological properties. One would usually prefer not to mix very diverse regimes within the same seismic source. On this basis, for the UK, one could begin by considering Chadwick et al.'s (1996) zones as a first approximation to seismic sources.

However, this has to be tempered by an admission that one can easily find regions that are diverse geologically, but similar in seismicity in that they have few or no earthquakes, Ireland being an obvious example. Equally, one can find areas that are similar geologically but dissimilar in seismicity, which one might expect to be related to variations in local stress conditions, unrelated to gross geological structure. While Chadwick et al (1996) attempted to deduce the location of stress concentrations from the interactions of structural blocks, the simplest indication is inevitably the seismicity pattern itself.

While it might be objected that the earthquake catalogue is short with respect to geological time, what matters in PSHA is the human time frame. It is a common misperception that the " 10,000 year return period ground motion" somehow relates to a 10,000 year period during which conditions might change, for instance, with renewed glaciation. This is, of course, an error. The hazard analyst is actually calculating the ground motion for next year that has a 0.0001 probability. Even if an earthquake catalogue is only 200 years long, one might reasonably expect that any patterns observable over that period will continue to be observable for the next few years to come.

It is sometimes asserted (usually without evidence) that uneven distribution of seismicity in an area is a chance artefact of a catalogue that is short compared to the seismic cycle. In fact, this assertion can be statistically tested (Musson 2000); if the clustering cannot be explained by chance, this has to be taken into account in the modelling.

To this end, Musson and Sargeant (2007) approached the Chadwick et al (1996) seismotectonic model in the following manner. Firstly, aseismic zones were ignored (there was no background zone, and the model did not tesselate over the whole British Isles). There is no practical advantage in dividing up aseismic areas according to geology; 
they will be assessed in the same way and inevitably come out with the same very low results.

Secondly, zones that appeared to be closely similar, especially with respect to seismicity, were merged. Thus seismotectonic zones $\mathrm{SC} 7$ and $\mathrm{SC} 8$ became seismic source zone SC78. These both reflect parts of the course of the Great Glen Fault, an ancient strike-slip fault now heavily eroded. While it was considered in the past that this fault might be an active source of earthquakes (e.g. Davison 1924), since many epicentres are off the fault zone itself, it is more likely that the fault creates a zone of weakness of some width (Musson 2007).

Thirdly, zones that appeared strongly inhomogeneous with respect to seismicity were divided into high and medium parts, or occasionally high, medium and low. Thus seismotectonic zone SC4 became seismic source zones SC4H and SC4M; the remainder of SC4 was simply dropped from the model. This is necessary to preserve the condition of PSHA that seismicity within any source should be homogeneous. If a single zone is drawn in such a way that half of it is aseismic, while the other half is active, the PSHA calculations, which are predicated on the principle that an earthquake has an equal probability of occurring at any point, will be invalid. Given that activity within any source zone will be computed from the observed historical seismicity, it is an absolute requirement of PSHA that clustered zones, where the seismicity is unequally distributed, must be avoided (Musson 2000).

While this means that the Musson and Sargeant (2007) is still based to some extent on the distribution of earthquakes in the historical catalogue, in contrast with some earlier models, it has a tectonic basis tempered by seismicity, rather than having started from the earthquake catalogue.

The resulting source zone model is shown in Figure 7.

Since 2007, this model has been developed further, primarily in the context of the SHARE project (Seismic Hazard Harmonisation in Europe), where it has been integrated with models for Norway, the Netherlands, Belgium, France and the Atlantic, producing a harmonised model for the whole North European area (Giardini et al 2009).

\section{Conclusions}

This historical perspective shows that in the evolution of seismic hazard models for the UK there has been a general progression towards a greater primacy of tectonic information. The earliest studies dispensed with tectonic information entirely; as the subject has matured, it has been recognised that relying entirely on a short earthquake catalogue is insufficient, and one can have more confidence in a model that is at least partly underpinned by consideration of the fundamental seismogenetic processes.

It has been generally acknowledged that, inevitably, a balance has to be struck between a purely seismicity-based approach and a purely geologically-based approach. Musson and Winter (2011) demonstrate the pitfalls that the latter approach can fall into. The choice is therefore whether one starts with the seismicity, and moderates the zonation based on the geology, or starts with the geology and moderates the zonation based on the seismicity. Arguably, the latter approach is more logical, since it starts with the fundamentals and 
gradually adds the details. At present it seems unrealistic to do away entirely with seismicity as a guide to seismic source modelling.

It would be difficult to summarise adequately the quantative effect of this general change in balance of modelling priorities. Not only will it be different in some areas compared to others, overall values have changed over the years due to succeeding generations of strong ground motion models. What one might hope is that the real change has been towards a greater robustness of results.

Obviously, experience in other countries will differ. The UK is perhaps unusual in that a probabilistic approach was pursued from the very start, and at no time was there any serious interest in deterministic approaches to seismic hazard. It is hoped that this historical account will still be of interest to hazard practitioners in other countries, who will be able to compare the experience outlined above with the pattern of development in their own country.

\section{Acknowledgements}

This paper started life as a presentation to the 2010 General Assembly of the European Seismological Commission, and I am grateful to the various people who urged me to write it up subsequently; also to Susanne Sargeant of BGS for commenting on the draft. Figure 3 appears with the permission of British Energy. The paper is published with the approval of the Executive Director of the British Geological Survey (NERC).

\section{References}

Abrahamson, N.A., Birkhäuser, P., Koller, M., Mayer-Rosa, D., Smit, P., Sprecher, C., Tinic, S. and Graf, R., 2002. PEGASOS - A comprehensive probabilistic seismic hazard assessment for nuclear power plants in Switzerland. 12th European Conference on Earthquake Engineering, 8. London.

Ambraseys, N.N. and Melville, C.P., 1983. The seismicity of the British Isles and the North Sea, SERC Marine Technology Centre Report.

Arup, 1993. Earthquake hazard and risk in the UK. Dept. of Environment, HMSO, London. Bender, B.K. and Perkins, D.M., 1987. SEISRISK III: a computer program for seismic hazard estimation, USGS Bulletin, USGS.

Bernreuter, D.L., Savy, J.B., Mensing, R.W. and Chen, J.C., 1989. Seismic hazard characterisation of 69 nuclear power plant sites east of the Rocky Mountains, Report. US Nuclear Regulatory Commission, US Nuclear Regulatory Commission.

Booth, E., 2008. UK studies for the preparation of the UK National Annex to Eurocode 8. Seismic risk in northern Europe. Liege, Belgium.

Bommer, J.J., Douglas, J., Scherbaum, F., Cotton, F., Bungum, H. and Fäh, D., 2010. On the selection of ground-motion prediction equations for seismic hazard analysis. Seismological Research Letters, 81, 783-793. 
Burton, P.W., Musson, R.M.W. and Neilson, G., 1984. Studies of historical British earthquakes. BGS Global Seismology Report.

Chadwick, R.A., Pharaoh, T.C., Williamson, J.P. and Musson, R.M.W., 1996. Seismotectonics of the UK, Technical Report WA/96/3C. British Geological Survey.

Cornell, C.A., 1968. Engineering Seismic Risk Analysis. Bulletin of the Seismological Society of America, 58, 1583-1606.

Davison, C., 1900. Scales of seismic intensity. Philosphical Magazine, 50, 44-53.

Davison C., 1924. A history of British earthquakes.Cambridge University Press, Cambridge.

EQE International Ltd, 2002. Seismic hazard: UK continental shelf. Health and Safety Executive Offshore Technology Report 2002/005.

Frankel, A., Mueller, C., Barnhard, T., Perkins, D., Leyendecker, E.V., Dickman, N., Hanson, S. and Hopper, M., 1996. National seismic-hazard maps: Documentation, Open File Report 96-532. USGS, USGS.

Giardini, D., Woessner, J. and Anderson, G., 2009. Seismic hazard and risk assessment: Upcoming European and global programs. CSEM/EMSC Newsletter, April 2009, 30-32.

Grünthal, G., Bosse, C., Musson, R.M.W., Gariel, J.-C., Crook, T.d., Verbeiren, R., Camelbeeck, T., Mayer-Rosa, D. and Lenhardt, W., 1996. Joint seismic hazard assessment for the central and western part of GSHAP Region 3 (Central and Northwest Europe). In: Thorkelsson, B. (Ed), Seismology in Europe. Icelandic Met. Office, Icelandic Met. Office, 339-342.

Grünthal, G., Bosse, C., Sellami, S., Mayer-Rosa, D. and Giardini, D., 1999. Compilation of the GSHAP regional seismic hazard for Europe, Africa and the Middle East. Annali di Geofisica, 42, 1215-1223.

Irving, J., 1979. An analysis of seismic risk in Great Britain. CEGB Report GD/PE-N/279(B). Irving, J., 1982. Earthquake hazard. CEGB/GDCD Report C/JI/SD/152.0/R019.

Jiménez, M.J., Giardini, D., Grünthal, G. and the SESAME Working Group, 2001. Unified seismic hazard modeling throughout the Mediterranean region. Bolletino di Geofisica Teorica ed Applicata, 42, 3-18.

Knopoff, L. and Kagan, Y.Y., 1977. Analysis of the theory of extreme values as applied to earthquake problems. Journal of Geophysical Research, 82, 5647-5657.

Lilwall, R.C., 1976. Seismicity and seismic hazard in Britain, IGS Seismological Bulletin. Institute of Geological Sciences.

Milne, W.G. and Davenport, A.G., 1969. Distribution of earthquake risk in Canada.Bulletin of the Seismological Society of America. Bulletin of the Seismological Society of America, 59, 729-754. Muir Wood, R., 1989. Fifty million years of "'passive margin"" deformation in North West Europe. In: Gregersen, S. and Basham, P.W. (Eds), Earthquakes at North Atlantic passive margins: Neotectonics and postglacial rebound. Kluwer, 393-411.

Musson, R.M.W., 1997. Seismic hazard studies in the UK: Source specification problems of intraplate seismicity. Natural Hazards, 15, 105-119.

Musson, R.M.W., 2000. Evaluation of seismic hazard source models. In: Lapajne, J. and Vidrih, R. (Eds), Seismicity modelling in seismic hazard mapping. Slovenian Geophysical Survey, Slovenian Geophysical Survey, 53-66. 
Musson, R.M.W., 2004. Objective validation of seismic hazard source models. 13th World Conference on Earthquake Engineering, 2492. Vancouver.

Musson, R.M.W., 2007. British earthquakes. Proceedings of the Geologists’ Association, 118, 305-337.

Musson, R.M.W. and Winter, P.W., 1996. Seismic hazard of the UK. AEA Technology Report. Musson, R.M.W., Long, D., Pappin, J.W., Lubkowski, Z.A. and Booth, E., 1997. UK Continental Shelf seismic hazard, Offshore Technology Report. Health and Safety Executive.

Musson, R.M.W. and Winter, P.W., 1997. Seismic hazard maps for the UK. Natural Hazards, 14, 141-154.

Musson, R.M.W. and Sargeant, S.L., 2007. Eurocode 8 seismic hazard zoning maps for the UK. British Geological Survey Technical Report.

Musson, R.M.W., Sellami, S. and Brüstle, W., 2009. Preparing a seismic hazard model for Switzerland: The view from PEGASOS Expert Group 3 (EG1c). Swiss Journal of Geology, 102, 107-120.

Musson, R.M.W. and Winter, P.W., 2011. Objective assessment of source models for seismic hazard studies: with a worked example from UK data. Bulletin of Earthquake Engineering, DOI: 10.1007/s10518-011-9299-6.

Ottemöller, L., Nielsen, H.H., Atakan, K., Braunmiller, J. and Havskov, J., 2005. The 7 May 2001 induced seismic event in the Ekofisk oil field, North Sea. Journal of Geophysical Research, 110, B1030110.1029/2004JB003374.

Power, M., Chiou, B., Abrahamson, N.A., Bozorgnia, Y., Shantz, T. and Roblee, C., 2008. An overview of the NGA project. Earthquake Spectra, 24, 3-22.

Principia Mechanica Ltd, 1982. British earthquakes. Principia Mechanica Ltd Report.

Scherbaum, F., Delavaud, E. and Riggelsen, C., 2009. Model selection in seismic hazard analysis: An information-theoretic perspective. Bulletin of the Seismological Society of America, 99, 32343247.

Seismic Hazard Working Party, 1987. Report on seismic hazard assessment: Hinkley Point. CEGB Report.

Soil Mechanics Ltd., 1982. Reassessment of UK seismicity data: Bracknell. Soil Mechanics Ltd. Report.

Woo, G., 1996. Kernel estimation methods for seismic hazard area source modelling. Bulletin of the Seismological Society of America, 86, 353-362. 


\section{Figure captions}

Figure 1

UK seismicity ( $\geq 3.5 \mathrm{Mw}$ ) up to 2007 (the date of the last model considered in this paper).

Figure 2

First seismic hazard map of Great Britain, from Lilwall (1976).

Figure 3

A typical site-specific model from the 1980s, consisting of seven zones and one fault. The site is marked with a circle. Redrawn from SHWP (1987).

Figure 4

The "tectonic" seismic source model from Arup (1993). The zones are divided into three catagories by activity rate, here labelled "high", "medium" and "low".

Figure 5

The GSHAP/SESAME seismic source zones for the British Isles; this model evolved from previous models used for hazard mapping in the 1990s.

Figure 6

Seismotectonic model of the UK, redrawn from Chadwick et al (1996). CF $=$ Caledonian Foreland; SC = Scottish Caledonides; EC = English Caledonides; V = Variscides; NSB = North Sea basins.

Figure 7

Seismic source model from Musson and Sargeant (2007). 


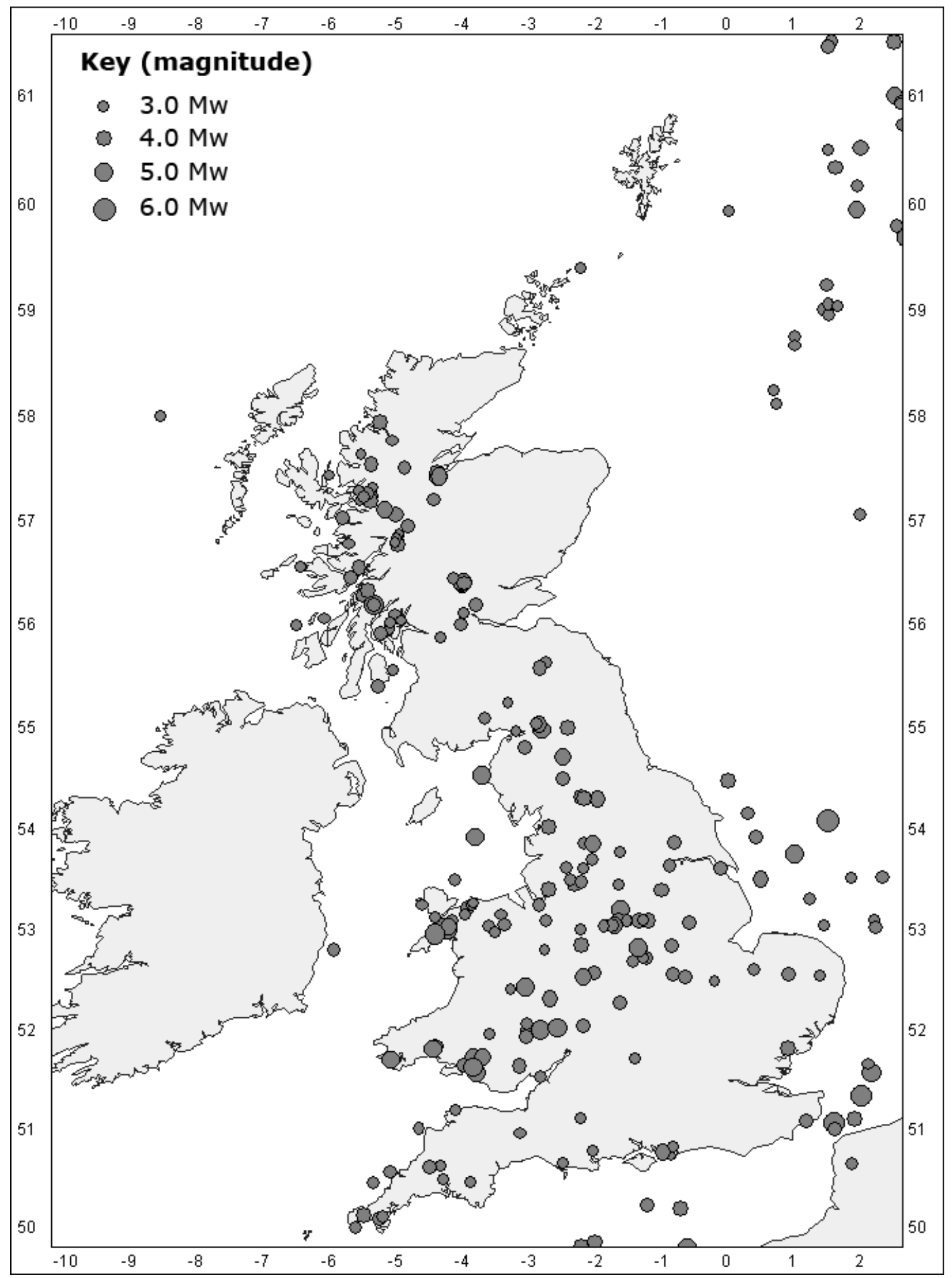

Figure 1 


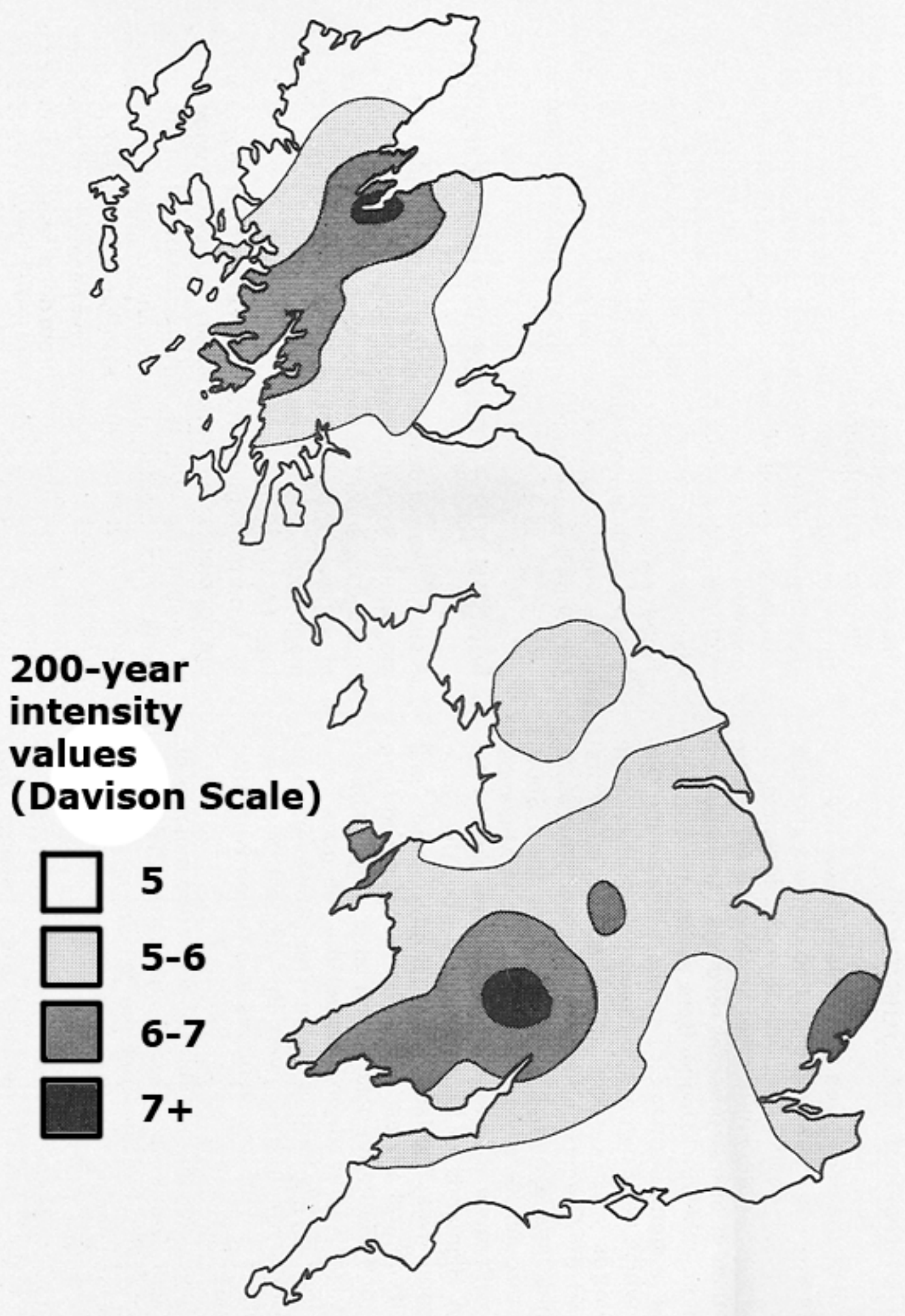

Figure 2 


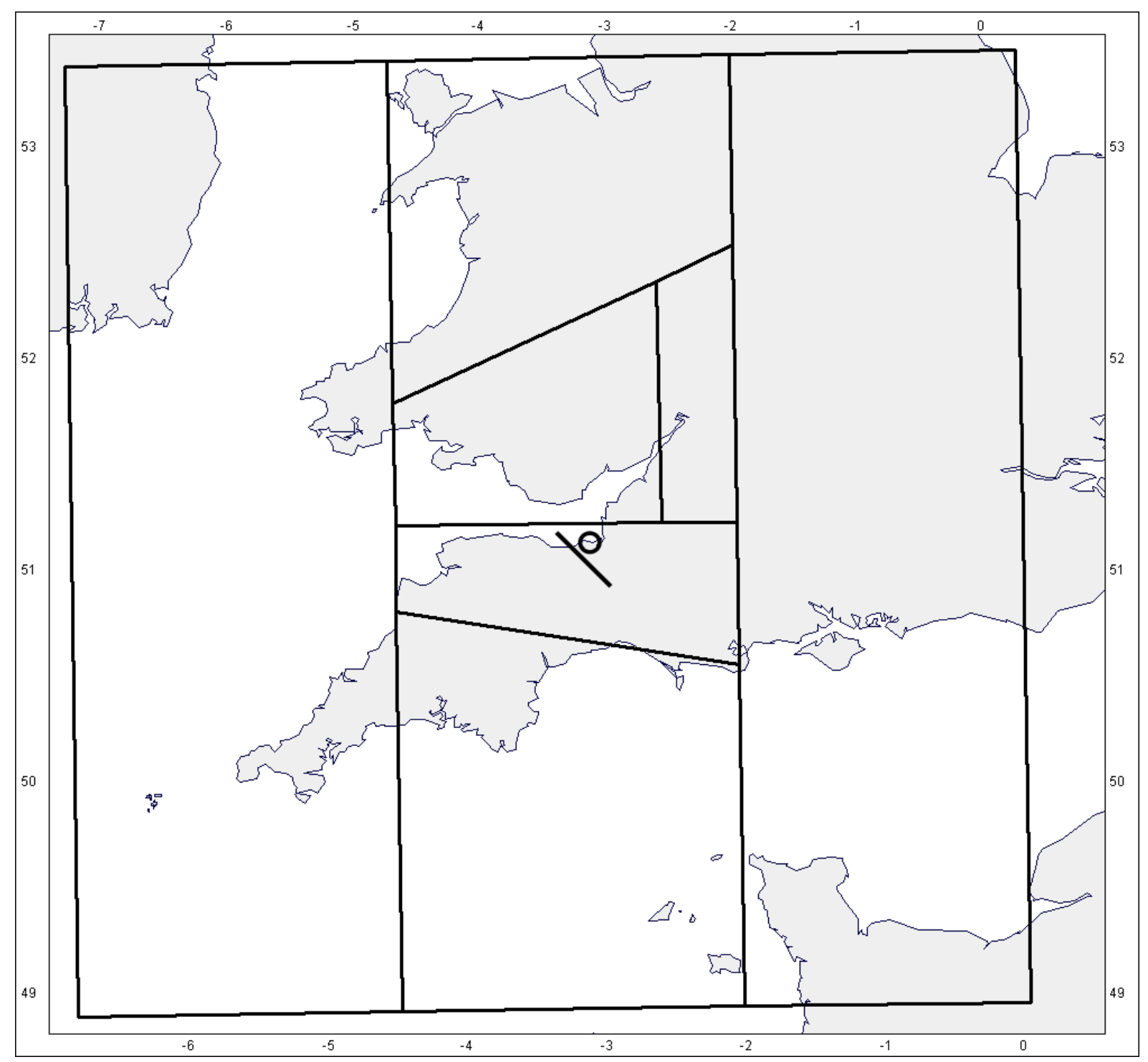

Figure 3 


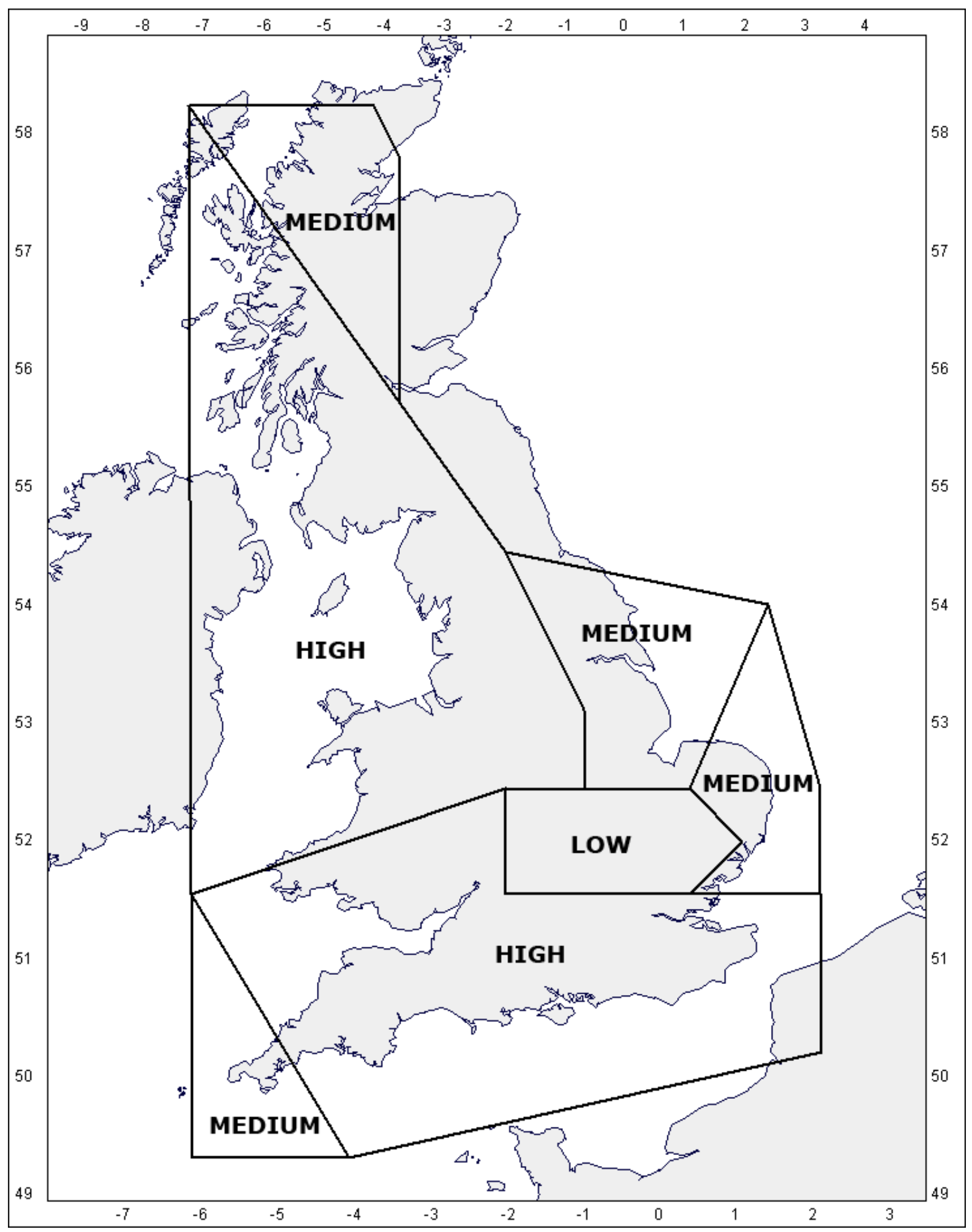

Figure 4

17 


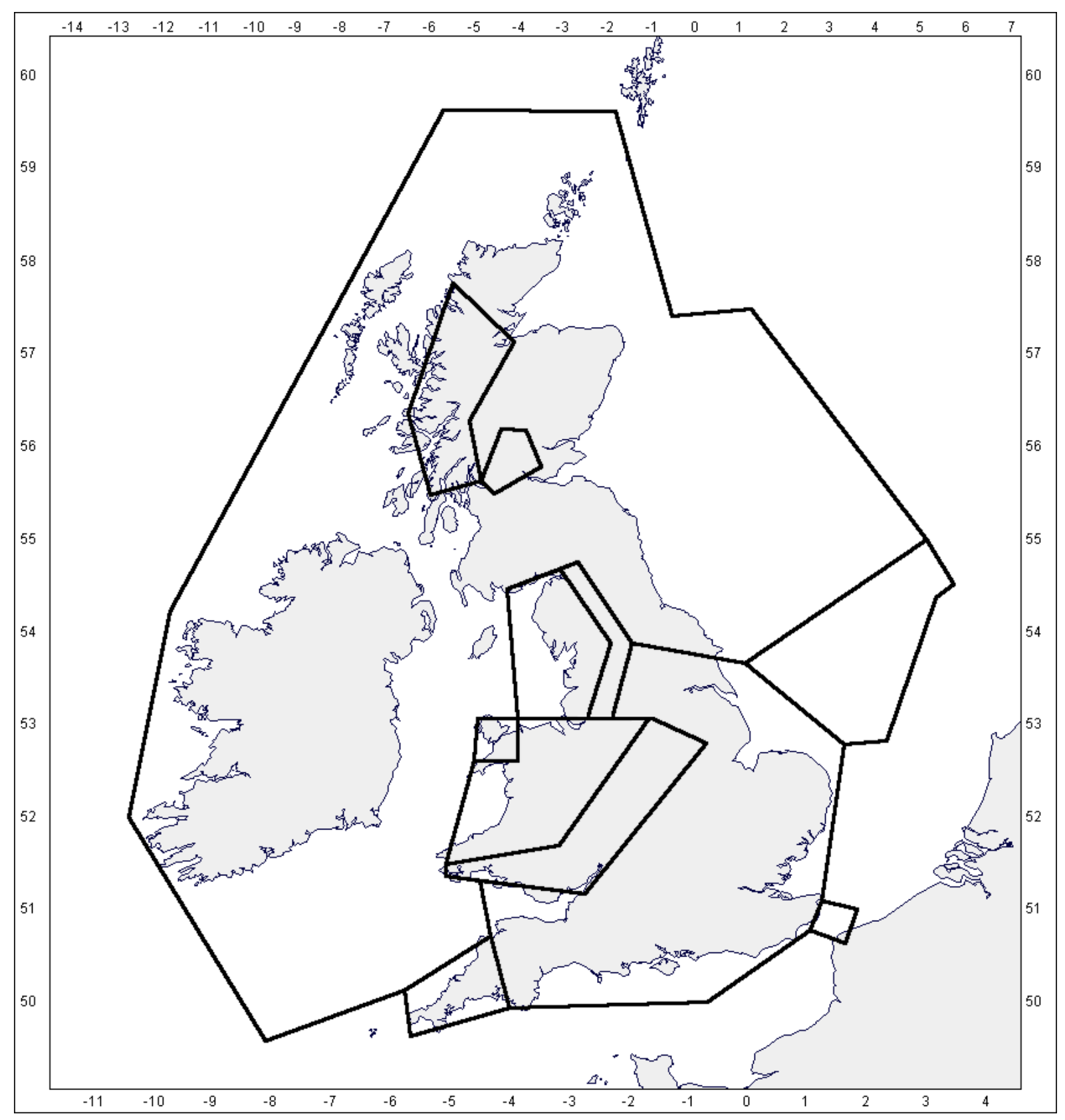

Figure 5 


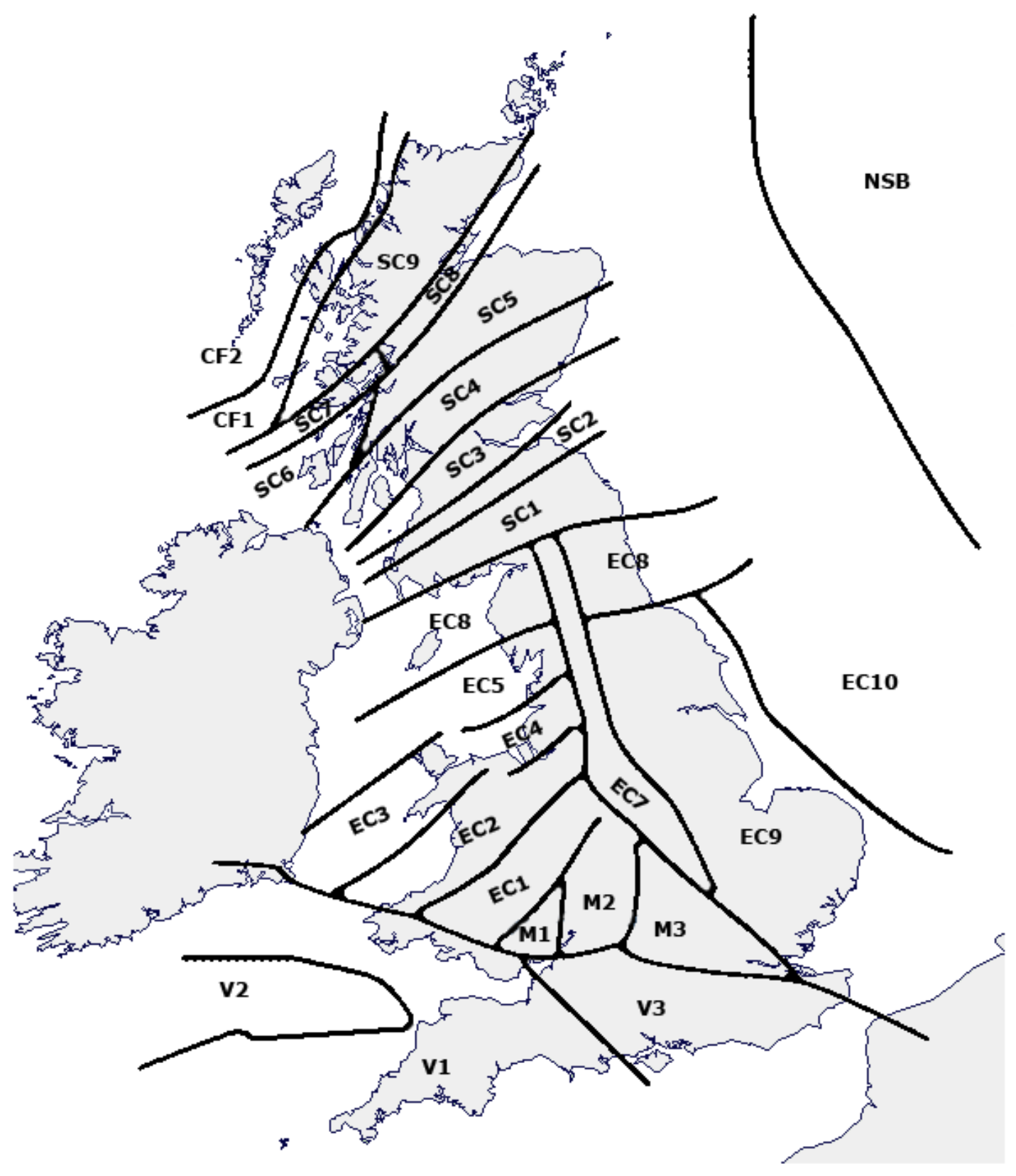

Figure 6 


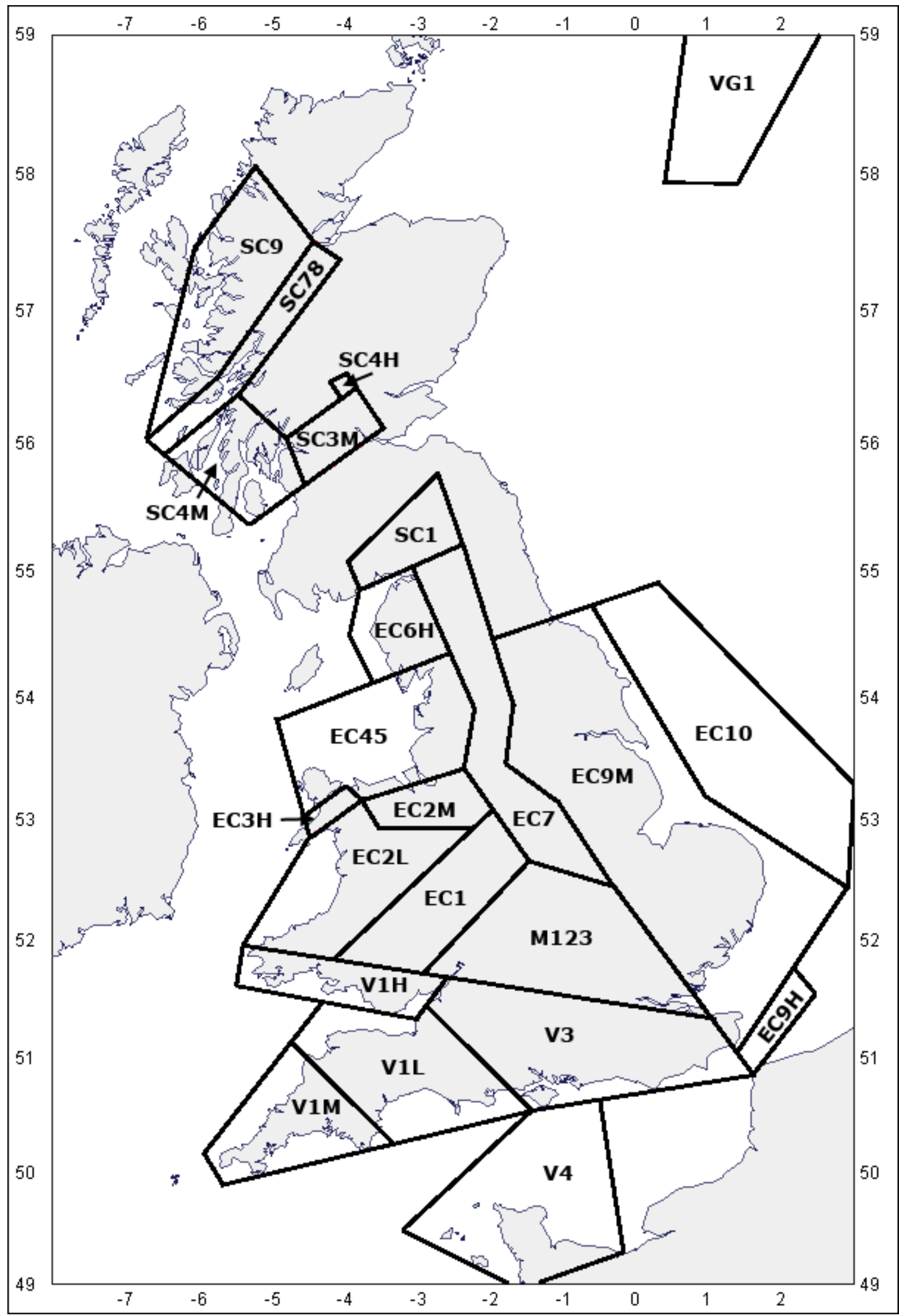

Figure 7 